\title{
Suppression of Infectious TMV Genomes Expressed in Young Transgenic Tobacco Plants
}

\author{
S. A. Siddiqui, ${ }^{1}$ C. Sarmiento, ${ }^{2}$ S. Valkonen, ${ }^{1}$ E. Truve, ${ }^{2}$ and K. Lehto ${ }^{1}$ \\ ${ }^{1}$ Laboratory of Plant Physiology and Molecular Biology, University of Turku, FIN-20014 Turku, Finland; ${ }^{2}$ Department of Gene \\ Technology, Tallinn University of Technology, 12618 Tallinn, Estonia
}

Submitted 26 April 2007. Accepted 3 August 2007.

Full-length cDNAs of the wild-type (wt) Tobacco mosaic virus (TMV) and of the coat protein gene-deleted $(\triangle \mathrm{CP})$ derivative of wt-TMV, under control of the $35 \mathrm{~S}$ promoter and downstream ribozyme sequence to produce accurate viral transcripts, were transformed to tobacco plants to analyze plant-virus interactions through different stages of plant development. Surprisingly, young wt-TMV transgenics accumulated only very low levels of viral RNA, remained free of symptoms, and were moderately resistant against exogenous inoculations. This early resistance caused significant stress to the plants, as indicated by reduced growth. Approximately 7 to 8 weeks after germination, the resistance was broken and plants developed typical wtTMV symptoms, with high accumulation of the viral RNAs and proteins. The $\triangle \mathrm{CP}$-TMV plants likewise were initially resistant to the endogenous inoculum and were stunted, although to a lesser extent than the wt-TMV plants. The resistance was broken at the same time as in the wt-TMV plants, but the mutant replicated to much lower levels and produced much milder symptoms than the wt virus. TMVspecific small interfering RNAs as well as increased transgene methylation were detected in the plants only after the resistance break, indicating that the resistance in the young plants was not due to RNA silencing.

Additional keywords: plant defense, silencing suppressors.

Virus disease symptoms on host plants are caused by combined effects of several virus-encoded factors and the host defense reactions. For Tobacco mosaic virus (TMV), it has been shown that the mosaic symptoms in systemically infected tobacco leaves are determined by the 126- or 183-kDa replicase proteins, and that the symptom severity is distinctly affected by specific amino acids of these proteins (Bao et al. 1996; Ding et al, 2004; Shintaku et al. 1996). Also, the TMV coat protein (CP) strongly affects symptoms, because different deletions of the $\mathrm{CP}$ gene may change the symptoms from very mild to very severe (Dawson et al. 1988; Lindbeck et al. 1992). Even the alteration of just one or two amino acids, which affect the folding of the $\mathrm{CP}$, can change the symptoms to very severe (Banerjee et al. 1995; Jockusck et al. 2001). Furthermore, the cell-to-cell movement protein (MP) is required not only for efficient virus spread and accumulation but also for the symptom production (Zvereva et al. 2004). Both MP and CP co-localize with the viral replication complexes (VRCs) and, therefore, may be required for either their efficient assembly or their function and, indeed,

Corresponding author: K. Lehto; Telephone: +358 2333 6266, Fax: +358 2333 5549, E-mail: klehto@utu.fi a reported CP mutant severely impairs the VRC formation (Asurmendi et al. 2004; Kawakami et al. 2004). Reduced virus accumulation and spread in different CP mutant strains and in mutants lacking $\mathrm{CP}$ completely may be due to the impaired replication of the mutants (Asurmendi et al. 2004; Kawakami et al. 2004) but also could be related, at least partially, to impaired local or systemic spread of the infection. In natural infections, all viral products are required for efficient accumulation of the others and, due to this interdependency, their separate roles in disease induction are complex and difficult to resolve.

The RNA silencing-mediated plant defense reactions as well as the virus-encoded silencing suppressors strongly affect the outcome of the disease and the severity of disease symptoms (Brigneti et al. 1998; Chapman et al. 2004; Dunoyer et al. 2004; Lecellier and Voinnet 2004; Voinnet 2005). Tobamovirusencoded replicase proteins have been described as suppressors of RNA silencing, and the symptom severity of different 126or $183-\mathrm{kDa}$ proteins' mutants was shown to correlate positively with the activity of the silencing suppression (Ding et al. 2004; Kubota et al. 2003). The dark green islands (DGI), a typical feature of the mosaic symptoms and of the disease phenotype of different viruses, most likely are caused by silencing-mediated defense reactions, as was reported for two different potyviruses (Moore et al. 2001; Yelina et al. 2002).

To dissect the symptom-causing mechanisms of TMV during different stages of plant growth, and particularly the role of $\mathrm{CP}$ in this process, we established an artificial infection system, where wild-type (wt) and CP-deleted ( $\Delta \mathrm{CP}) \mathrm{TMV}$ genomes were expressed in transgenic tobacco plants. This system allows the investigation of plant responses to viral infection at all stages of plant growth, even in the absence of cell-to-cell or long-distance movement. It also permits simultaneous maintenance of the virus and the activated host defenses, allowing visualization of their mutual long-term effects.

\section{RESULTS}

Resistance of young plants against endogenously expressed viral RNAs.

Expression of the full-length wt-TMV and $\triangle \mathrm{CP}-\mathrm{TMV}$ transcripts were confirmed for the R1 generation of wt-TMV and $\triangle C P-T M V$ transgenic plants (data not shown). Seedlings of the R2 generation of all analyzed transgenic lines germinated and grew through the early stages of development without showing any chlorotic or mosaic symptoms. However, both types of transgenic plants grew more slowly than the nontransgenic control plants and became more and more stunted even in the absence of any other symptom. At their full height, the wtTMV and $\triangle \mathrm{CP}-\mathrm{TMV}$ plants were approximately 50 to 70 and 20 to $30 \%$ smaller, respectively, than the nontransgenic control 
plants (Fig. 1A and B). During approximately the first 7 weeks of growth, either no ( $\triangle \mathrm{CP}-\mathrm{TMV})$ or very low (wt-TMV) levels of viral RNA were detected in the transgenic plants (Fig. 2B). TMV-specific small interfering (si)RNAs (if any) were below detection level during this time (Fig. 3).

The presence of infectious transcripts in the wt-TMV plants also was tested by inoculating their sap onto mature Nicotiana tabacum L. 'Xanthi' NN leaves. Inoculations done with sap of 3-week-old wt-TMV transgenic seedlings typically produced one to six lesions per inoculated leaf (data not shown), indicating that the infectious viral RNA was present in the leaves in very low amounts. However, extracts from 5- or 6-week-old wt-TMV transgenic seedlings which did not show any symptom by then produced high numbers (more than 100) of lesions, indicating that the virus RNA was replicating in the plants prior to the appearance of the viral symptoms.

When the transgenic plants were inoculated with TMV during these early weeks, they developed disease symptoms which appeared 2 to 7 days later and initially were much milder than in the TMV-inoculated nontransgenic control plants (Fig. 4A), and also remained relatively mild for several weeks after their appearance (Fig. 4B), indicating that the transgenic plants
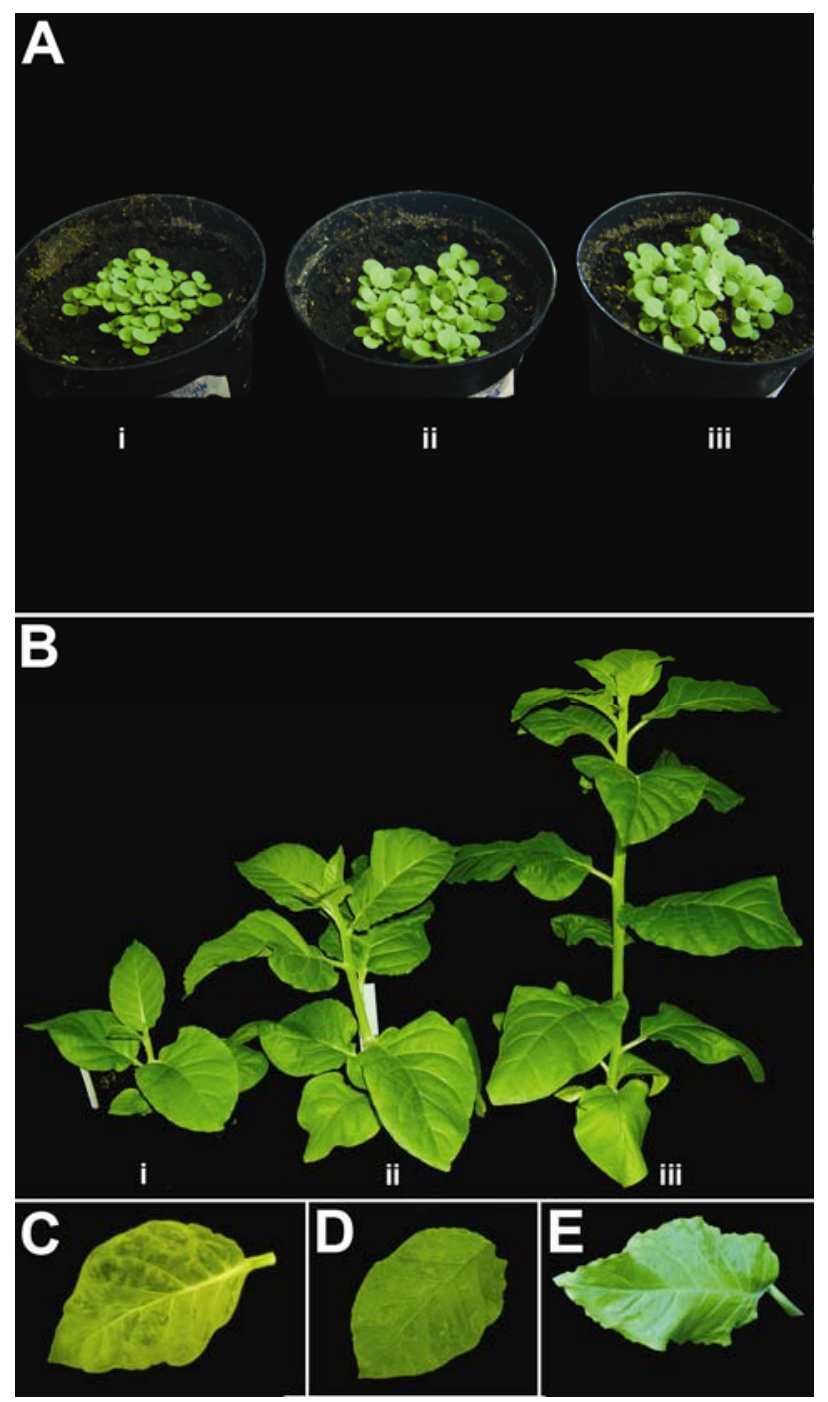

Fig. 1. Wild-type (wt) Tobacco mosaic virus (TMV) (i) and coat protein gene-deleted ( $\triangle \mathrm{CP})$-TMV (ii) transgenic plants, and wt control plants (iii), from left to right, at $\mathbf{A}, 1$ week and $\mathbf{B}, 7$ weeks after germination. Symptoms on a leaf of a C, wt-TMV transgenic plant, D, $\triangle \mathrm{CP}-\mathrm{TMV}$ transgenic plant, and $\mathbf{E}$, side shoot of a $\triangle \mathrm{CP}-\mathrm{TMV}$ transgenic plant. were moderately resistant against this virus. Still, inoculated viral RNA accumulated in transgenic plants to similar levels as in the wt plants already within the first week after inoculation (Fig. 4C and D).

Between 7 and 8 weeks after germination, resistance against virus replication in the transgenic plants was broken. Starting from the apical leaves, the wt-TMV transgenic plants showed typical systemic TMV symptoms (Fig. 1C), and genomiclength TMV RNA accumulated in the leaves to very high levels (Fig. 2A). Very mild symptoms (chlorotic spots) appeared occasionally in the $\triangle \mathrm{CP}-\mathrm{TMV}$ plants (Fig. 1D), and these accumulated low levels of the truncated genomic-length RNA (Fig. 2B). Interestingly, a TMV-specific RNA of approximately 210 nucleotides (nt), corresponding to the size of truncated $3^{\prime}$ terminal subgenomic mRNA, accumulated to high levels in these plants (Fig. 2A). At this stage, the TMV-specific 21- to 25-nt siRNAs also became detectable in the leaves and, in each type of transgenic plant, the accumulation of siRNAs correlated with the accumulation of viral RNA, being more abundant in the wt-TMV plants and less abundant in the $\triangle \mathrm{CP}$-TMV plants (Fig. 3). It is worth mentioning that more distinct virus symptoms developed in the $\triangle \mathrm{CP}-\mathrm{TMV}$ plants when the growth of the side shoots was induced by removal of the apexes and most of the mature leaves. However, the virus symptoms in the newly grown side shoots were not as severe as those developed in the wt-TMV plants (Fig. 1C and E). The viral RNA accumulated in these side shoots to similar levels as in intact $\triangle \mathrm{CP}$ TMV plants (Fig. 2A), but no TMV-specific siRNAs were detected (Fig. 3).

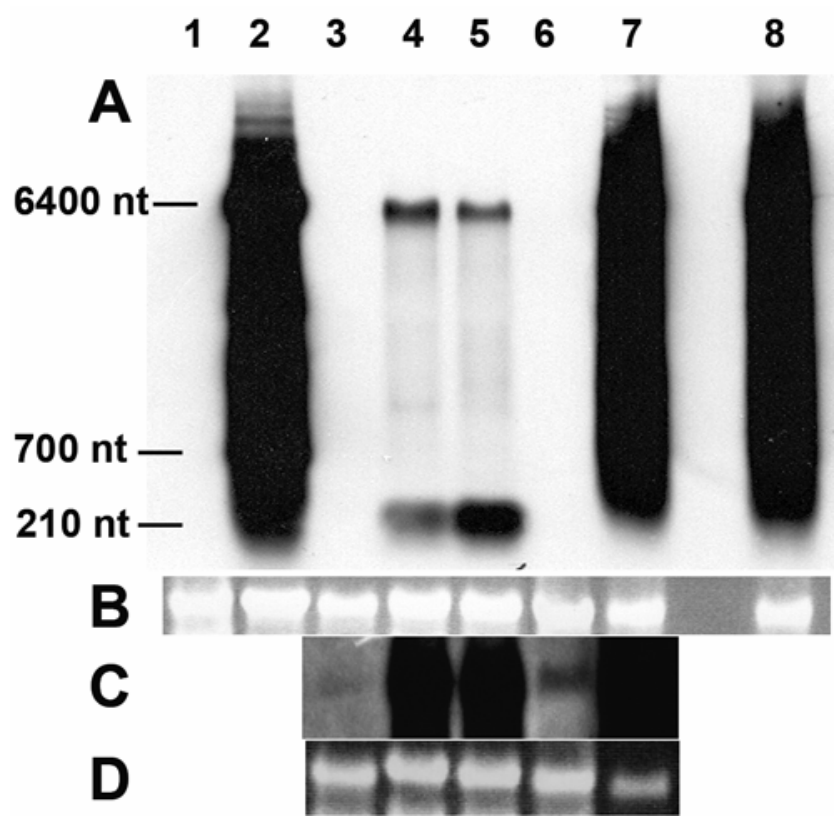

Fig. 2. Northern blot analysis of the Tobacco mosaic virus (TMV)-specific RNAs extracted from the upper leaves of TMV-inoculated wild-type plant and from transgenic tobacco plants at 4 weeks after germination (before resistance break) and at 8 weeks after germination (after resistance break). Lane 1, healthy control; lane 2, wild-type TMV-inoculated nontransgenic plant; lane 3 , coat protein gene-deleted $(\triangle \mathrm{CP})$-TMV transgenic plant before resistance break; lane $4, \Delta \mathrm{CP}-\mathrm{TMV}$ transgenic plant after resistance break; lane 5, $\triangle \mathrm{CP}$-TMV transgenic plant after resistance break, side shoots; lane 6, wt-TMV transgenic plants before resistance break; lanes 7 and 8 , wt-TMV transgenic plants after resistance break. In each lane, $5 \mu \mathrm{g}$ of total RNA was loaded, except for lane 7 , where $2 \mu \mathrm{g}$ of total RNA was loaded. A, Results are shown after 5 min of exposure. C, The same samples as in A, and $10 \mu \mathrm{g}$ of total RNA was loaded in each lane, except for lane 7 , where $2 \mu \mathrm{g}$ of total RNA was loaded. The results are shown after 5 $\mathrm{h}$ of exposure. B and D, Ethidium-bromide-stained rRNA loading controls, indicating the different amounts of RNA loaded. 
Accumulation of the virus-specific proteins.

After resistance break, the viral $126-\mathrm{kD}$ replicase protein, $\mathrm{MP}$, and $\mathrm{CP}$ were detectable by Western blot analysis from the samples of the wt-TMV transgenic plants (Fig. 5). The 126$\mathrm{kDa}$ replicase protein also was detectable, albeit on a very low level, from the $\triangle \mathrm{CP}-\mathrm{TMV}$ plants. Strikingly, the MP was detected in these plants on a much higher level than in the wtTMV plants (Fig. 5).

\section{DNA methylation.}

To test whether the initial TMV resistance or the change of the resistance status in the transgenic plants was correlated to methylation status of the transgene promoter or coding regions, their cleavage with methylation-sensitive Sau96I restriction enzyme was tested before and after the resistance break.

Polymerase chain reaction (PCR) fragments of expected sizes (1,509 and 1,033 nt for the wt- and $\triangle \mathrm{CP}-\mathrm{TMV}$ plants, respectively) were amplified from the undigested DNA samples extracted from the leaves collected at 4 or 8 weeks after germination (i.e., before or after the resistance break) (Fig. 6A). After Sau96I digestion, only a very faint PCR fragment was produced from the samples extracted from wt-TMV transgenic plants before resistance break, indicating low or no DNA methylation at the transgene coding region in the young, resistant plants (Fig 6A). Likewise, only a faint or no-PCR amplification was obtained from Sau96I-digested DNA samples of the $\Delta \mathrm{CP}$ TMV plants before resistance break. After the resistance break, higher amplification of the target fragments was obtained from the Sau96I-digested samples of both types of transgenic plants (Fig. 6A), indicating that the TMV cDNA methylation was induced or enhanced by the activation of the viral replication. Essentially the same results were obtained by digestion of the genomic DNA samples with the methylation-sensitive enzyme HpaII (with target sites in positions 5,208 and 5,456) (data not shown).

Amplification of the $35 \mathrm{~S}$ promoter sequence over nucleotides 1 and 421 produced the expected fragment from the undigested DNA samples of all transgenic plant samples. The Sau96I digestion completely abolished the amplification from samples collected prior to the resistance break, indicating that the promoter regions were not methylated at this stage. However, Sau96I-digested DNA, extracted from either the wt-TMV or $\triangle \mathrm{CP}$-TMV plants after the resistance break, produced a detectable PCR product (Fig. 6B), indicating that the methylation level of the promoter region also was increased after the resistance break.

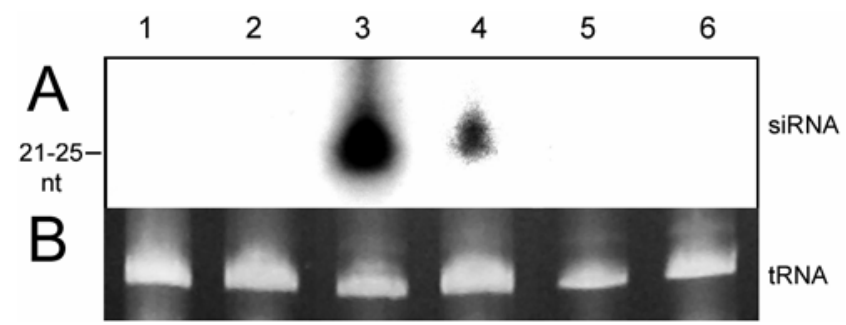

Fig. 3. A, Northern blot analysis of the Tobacco mosaic virus (TMV)-specific small interfering ( $\mathrm{si}$ )RNAs extracted from the leaves of transgenic tobacco plants at 4 weeks after germination (before resistance break) and at 8 weeks after germination (after resistance break). Total RNA (30 $\mu \mathrm{g})$ was loaded on each lane. Lane 1, wild-type (wt) control plant; lane 2, wt-TMV transgenic plant before resistance break; lane 3, wt-TMV transgenic plant after resistance break; lane 4 , coat protein gene-deleted $(\triangle \mathrm{CP})$-TMV transgenic plant after resistance break; lane 5, $\triangle \mathrm{CP}-\mathrm{TMV}$ transgenic plant before resistance break; lane $6, \Delta \mathrm{CP}-\mathrm{TMV}$ transgenic plant after resistance break, side shoots. B, Ethidium-bromide-stained rRNA loading controls.

\section{DISCUSSION}

All the TMV-encoded proteins are essential for efficient virus infection; however, due to their multiple and overlapping functions, their individual roles are difficult to dissect. Transgenic tobacco lines, which constitutively express infectious transcripts either of the wt viral genome or a mutant genome with the $\mathrm{CP}$ gene deleted, allow the analysis of host-TMV interactions, as well as the role of $\mathrm{CP}$ in the TMV replication and symptom induction in a movement-independent situation through all developmental stages of the host.

Expression of the same wt-TMV cDNA construct in transgenic tobacco plants and production of typical wt virus symptoms have been reported earlier (Turpen et al. 1993); however, in this case, no attention was given to the differences in the symptomatology during various stages of plant growth. Here, we show that the disease phenotype (i.e., the plant response to the endogenous virus infection) changed during the growth. Initially, upon germination, the transgenic plants appeared healthy, without viral symptoms. A low level of the wt viral RNA was detected in the transgenic plants, but they appeared resistant against this endogenous inoculum. This initial resistance appeared to function both via inhibition of replication of the viral transcripts and also after the accumulation (replication) of the viral genomic RNA, via delayed appearance of the disease symptoms. Resistance against the symptom development also was observed when the symptomless transgenic plants were externally inoculated with TMV. The symptoms appeared in these plants later and initially were much milder than in the inoculated wt control plants, although the viral RNA accumulated at the same rate and to comparable levels in both types of plants. Plants at the young, resistant stage lacked detectable levels of TMV-specific siRNAs, and the transgene

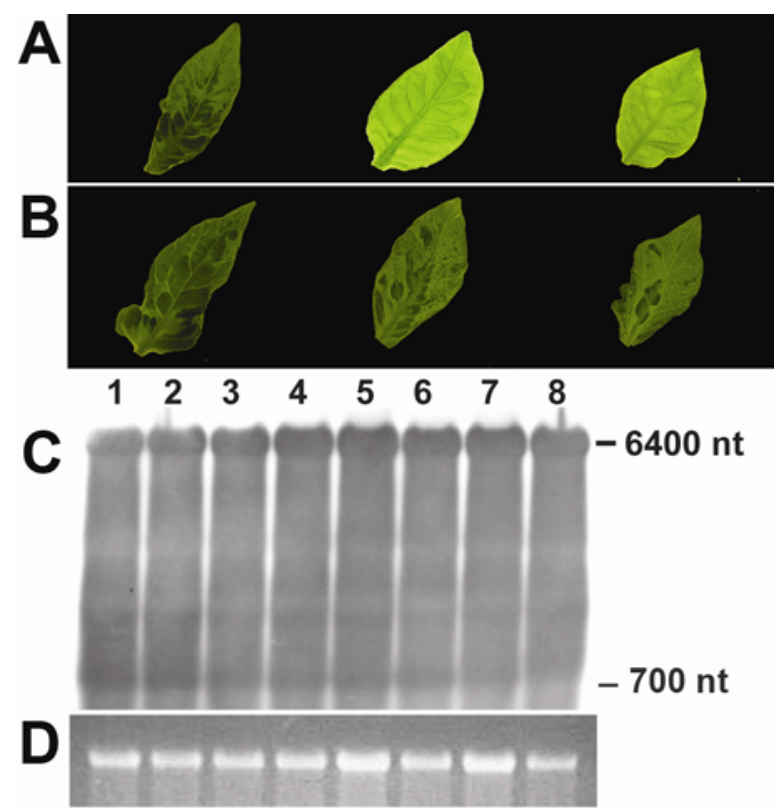

Fig. 4. A and B, Tobacco mosaic virus (TMV) symptoms and $\mathbf{C}$, and $\mathbf{D}$, detection of the TMV-specific RNAs from the TMV-inoculated control and transgenic plants. Symptoms on the wild-type (wt) plants and on wtTMV and coat protein gene-deleted $(\triangle \mathrm{CP})$-TMV-transgenic plants (from left to right) inoculated at 4 weeks after germination and observed at $\mathbf{A}, 14$ days post inoculation (dpi) and B, 25 dpi. C, Northern blot analysis of the TMV-specific RNAs extracted from the upper leaves of the inoculated plants at 4 (lanes 1 to 4 ) and 5 (lanes 5 to 8 ) weeks after germination, and sampled 1 week after inoculation (before resistance break). Lanes 1 and 5 , wt control plant; lanes 2 and 6, $\triangle \mathrm{CP}$-TMV transgenic plants; lanes 3, 4, 7, and 8 , wt-TMV transgenic plants. A, Total RNA $(2 \mu \mathrm{g})$ was loaded in each lane. D, Ethidium-bromide-stained rRNA loading controls. 
coding region remained mostly unmethylated. Thus, RNA silencing against TMV appeared not to play a major role for the protection against the viral RNA present in the plant cells. The protection, however, caused a considerable stress to the plants, because the plant growth was strongly reduced during this stage, even in the absence of accumulation of hardly any viral products. Strikingly, the resistance status was consistently broken, in a very repeatable fashion, when the plants were approximately 7 to 8 weeks old.

After the breaking of the resistance, the wt-TMV transgenic plants rapidly developed strong mosaic symptoms of TMV and accumulated the viral genomic RNA, replicase protein, MP, and CP. At this stage, the leaves also accumulated virus-specific siRNAs, and the viral transgenic DNA became more methylated, indicating that the RNA silencing became (more) active. Still, in spite of this fully activated defense response, the virus infection was effectively propagated.

Analogously to the wt-TMV transgenic lines, the TMV transgenic lines with the $\mathrm{CP}$ gene deleted also initially were symptomless and produced no detectable levels of viral RNA. In these plants, the transgene coding region appeared only slightly methylated as in the wt-TMV transgenic plants, no viral siRNAs were detected in the leaves, and the plants were moderately resistant to the exogenous inoculations. Thus, an active protection mechanism was suppressing viral replication also in these plants and also reduced the growth of the plants, although not as much as in the wt-TMV transgenics. The resistance in the $\triangle \mathrm{CP}-\mathrm{TMV}$ plants broke at approximately the same time as in the wt-TMV plants. Upon the resistance break, the $\triangle \mathrm{CP}-\mathrm{TMV}$ plants developed very mild chlorotic spot symptoms and accumulated very low levels of the truncated viral genomic RNA, in accordance with the earlier results showing that $\mathrm{CP}$ is necessary both for efficient virus replication and for symptom production (Asurmendi et al. 2004; Dawson et al. 1988; Kawakami et al. 2004). Interestingly, these plants accumulated high levels of a short viral RNA (210 nt) corresponding to the truncated CP subgenomic mRNA, and also of the MP, indicating that both the transcriptional and translational regulation of the internal genes were disturbed by the deletion of the $\mathrm{CP}$ coding region. The increase of the MP expression in $\triangle \mathrm{CP}$ virus constructs has been reported before and has been explained to be due to a higher expression of the genes at the $3^{\prime}$ proximal position in the TMV genome (Culver et al. 1993). Detection of TMVspecific siRNAs (Fig. 3) indicated that the RNA silencing

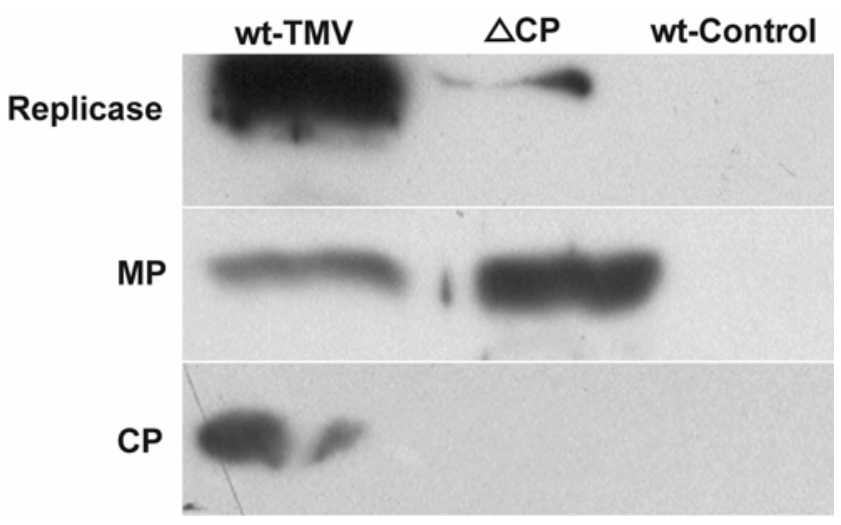

Fig. 5. Western blot analysis of the Tobacco mosaic virus (TMV)-specific replicase protein $(126 \mathrm{kDa})$, movement protein $(\mathrm{MP})(32 \mathrm{kDa})$, and coat protein $(\mathrm{CP})(17.5 \mathrm{kDa})$ from the leaves of wild-type (wt)-TMV and $\mathrm{CP}$ gene-deleted $(\triangle \mathrm{CP})$-TMV transgenic plants and from healthy control plants. The proteins were analyzed from the same protein extracts, with equal loading in each well. Equal concentrations of the extracts were confirmed by a Coomassie-blue staining of a parallel gel (not shown). also was activated after resistance break in these plants; however, in spite of the low viral replication potential and low level of silencing suppressor (the replicase protein) produced, it was not able to suppress the infection completely.

The mechanisms for resistance against endogenous virus infection in young tobacco plants or the reasons for the resistance failure at a later stage are not clear. Although the virus accumulates in $\triangle \mathrm{CP}$ plants at much lower levels than in the wt-TMV plants (Fig. 2A), the resistance break occurred at the same time in all different transgenic lines. The remarkably low replication potential of the $\triangle \mathrm{CP}$-TMV indicated that the breaking of resistance was not determined by accumulation of the viral products (RNA or silencing suppressor protein) to a certain threshold level. The available data most consistently suggest that the breaking of the resistance was associated with some specific alteration in the physiological status of the plants, at approximately 7 to 8 weeks after germination, which finally allowed strong replication of the virus. This specific physiological stage was indicated by the highly repeatable resistance break-up time. Also, the stronger symptoms in the side shoots of the $\triangle \mathrm{CP}-\mathrm{TMV}$ plants compared with the main shoots of these plants may be related to the different physiological status of the tissues. However, we are not aware of any specific physiological or gene expression alteration that should take place in plants at this developmental stage. The accumulation of virus-specific siRNAs after the resistance break, most prominently in wt-TMV plants, probably was due to the high concentration of the precursor RNA for siRNAs and was not the hallmark of strong resistance against TMV. Taking into account also the protection against external TMV inoculations before resistance break,

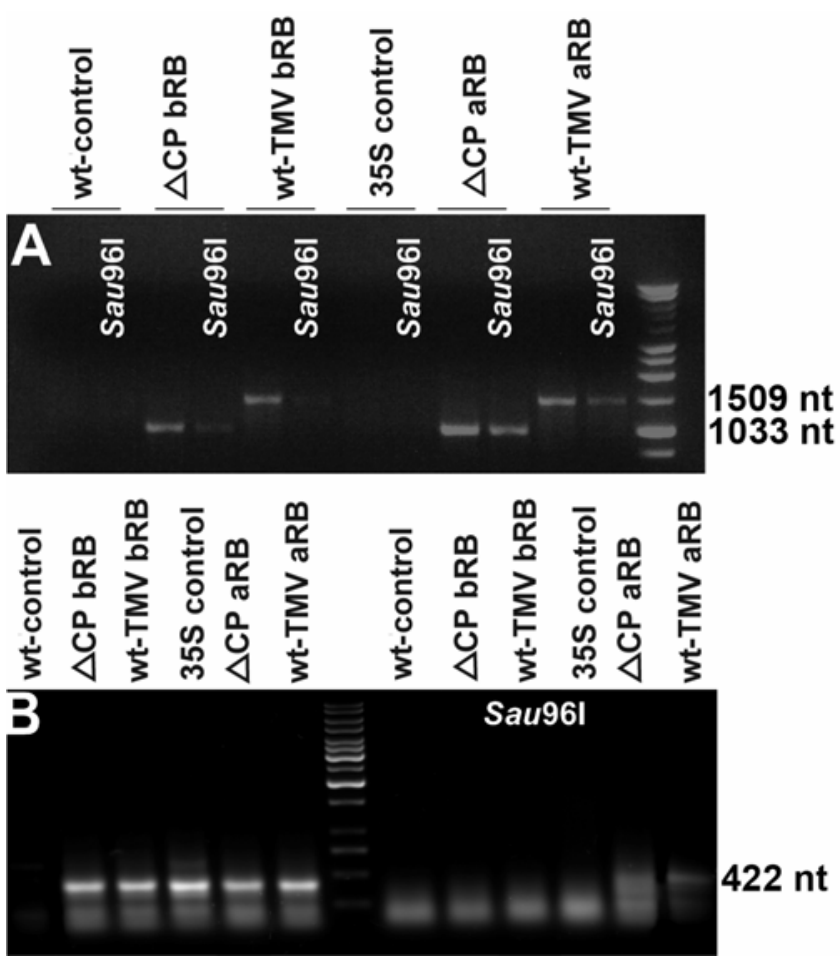

Fig. 6. Methylation analysis of the wild-type Tobacco mosaic virus (wtTMV) and coat protein gene-deleted ( $\triangle \mathrm{CP}$ )-TMV transgene $\mathbf{A}$, coding and $\mathbf{B}$, promoter regions, tested by polymerase chain reaction (PCR) amplification from either the undigested DNA templates or templates digested with methylation-sensitive Sau96I enzyme. Samples and their digestion treatments are indicated above the lanes. $\mathrm{bRB}=$ before resistance break and $\mathrm{aRB}=$ after resistance break. Sizes of the expected PCR products are indicated. $35 \mathrm{~S}$ control $=$ sample from nonrelated transgenic plant, carrying $35 \mathrm{~S}$ promoter. 
we conclude that the interplay between TMV and the host, at least in the case of a transgene-derived virus, is not regulated by RNA-dependent pathways only.

\section{MATERIALS AND METHODS}

Virus and plant material.

The 35S-promoter-regulated cDNA construct of TMV genomic RNA, pBGC89, was a kind gift of T. Turpen (Turpen et al. 1993). In this construct, the full-length genome of U1 strain of TMV, derived from the infectious clone pTMV204 (Dawson et al. 1988), has been fused to the $35 \mathrm{~S}$ promoter so that the transcription initiates from the first nucleotide of the TMV genome. A synthetic self-cleaving ribozyme sequence has been inserted at the $3^{\prime}$ of the TMV sequence, to remove all but three non-TMV nucleotides at the $3^{\prime}$ end of the transcripts. Progeny virus derived from the R0 plants, transformed with pBGC89, has been analyzed earlier and found identical to virus produced from infectious transcripts (Turpen et al. 1993).

The $\Delta \mathrm{CP}$ version of the wt genome was introduced into pBGC89 via swapping the $3^{\prime}$ terminal portion of the $\triangle \mathrm{CP}$ clone S3-28 for the $3^{\prime}$ portion of the wt clone (Dawson et al. 1988), using the unique sites HpaI (TMV genomic nucleotide 3,230) and BsiW1 (nucleotide 6,245). Restriction enzymes, ligases, and polymerases were purchased from New England Biolabs (Ipswich, MA, U.S.A.). The whole expression cassettes were transferred into the binary transformation vector pGA482 (An 1986), transformed into N. tabacum L. 'Xanthi' nn plant tissues, and regenerated on kanamycin selection by standard methods (Smith et al. 1994). Transgenic plants (wtTMV and $\triangle$ CP-TMV) were propagated in a greenhouse at $25^{\circ} \mathrm{C}$ under a $16-\mathrm{h}$ photoperiod. Three R2 independent lines were used for the analysis described above.

The wt-TMV inoculums were derived from the sap of tobacco plants infected with the same cDNA clone that had been used for the transgene (i.e., pTMV304, a T7-promoter-controlled derivative of the original infectious clone pTMV204) (Dawson et al. 1986). Infected leaves were ground in $50 \mathrm{mM}$ phosphate buffer ( $\mathrm{pH}$ 7.0) and the sap was rubbed onto Carborundum-dusted lower leaves of transgenic plants. Likewise, for testing the infectivity of the young transgenic plants, the leaves were ground in $50 \mathrm{mM}$ phosphate buffer and the sap was inoculated onto N. tabacum L. 'Xanthi' NN leaves.

\section{RNA extractions, Northern blot, and siRNA analysis.}

Total RNA was extracted from transgenic plants before and after the appearance of viral symptoms (4- and 8-week-old plants) as described by Sijen and associates (1996). Northern blot detection of viral RNAs was done using digoxigeninlabeled, PCR-synthesized probes, using primers 5'-GTTTGTT TAAAGATGGCTC-3' and 5'-TGGGCCCCTACCGGG-3', annealing to TMV genomic positions 4,891 to 4,909 and 6,381 to 6,393 , according to the manufacturer's instructions (Roche, Mannheim, Germany). Analysis of TMV-specific siRNAs was performed according to Sarmiento and associates (2006) using $30 \mu \mathrm{g}$ of total RNA. The radioactive probe was a ${ }^{32} \mathrm{P}$-labeled in vitro transcript corresponding to the antisense strand of the viral RNA covering MP, CP, and 3' untranslated region sequences. Radioactive signals were detected with Personal Molecular Imager FX (BioRad, Hercules, CA, U.S.A.).

\section{Protein extraction and Western immunoblotting.}

TMV 126-kDa replicase protein, MP, and CP were extracted from leaf tissues as described by Lehto and associates (2003), separated by sodium dodecyl sulfate polyacrylamide gel electrophoresis, and analyzed by Western blotting using chemiluminescence for detection, as described earlier (Lehto et al.
2003). The 126-kDa replicase and MP antisera were kind gifts of Y. Dorokhov and T. Ahola, respectively (Ahola and Kääriäinen 1995; Zvereva et al. 2004).

\section{Methylation analysis.}

The methylation of the transgenic coding and promoter regions was analyzed as described by Mallory and associates (2001) and Rodman and associates (2002) using methylationsensitive restriction enzyme Sau96I for digesting the plant genomic DNA samples. Restriction sites for the Sau96I enzyme are located at several nucleotide positions along the transgenic sequences, including positions 242 and 254 in the $35 \mathrm{~S}$ promoter (counting from the beginning of the promoter sequence) and positions 5,455 and 5,456 in the wt-TMV cDNA. DNA samples were extracted from the wt-TMV and $\triangle \mathrm{CP}-\mathrm{TMV}$ plants both before ( 4 weeks old) and after ( 8 weeks old) the resistance break, using cetyltrimethylammonium bromide (CTAB) extraction buffer (2\% CTAB, $1.4 \mathrm{M} \mathrm{NaCl}, 20 \mathrm{mM}$ EDTA, $10 \mathrm{mM}$ Tris- $\mathrm{HCl}, \mathrm{pH} 8.0$, and $0.3 \% \beta$-mercaptoethanol) and an equal volume of chloroform, with incubation at $65^{\circ} \mathrm{C}$, followed by repeated phenol-chloroform-isoamyl alcohol extractions and ethanol precipitation. Aliquots of the plant genomic DNAs were digested with the methylation-sensitive enzyme Sau96I. Fragments of the viral genomic sequences as well as of the $35 \mathrm{~S}$ promoter sequence were amplified by PCR from both the Sau96I-digested and undigested samples using Taq polymerase and primers annealing in TMV nucleotides 4,891 to 4,909 and 6,381 to 6,393 (the same as the ones used for the probe), or annealing in $35 \mathrm{~S}$ promoter nucleotides 1 to 20 (5'-GTCAACATGGTGGAGCACGA-3') and in nucleotides 396 to 421 (5'-TCCTCTCCAAATGAAATGAACTTCC-3'). The amplified products were analyzed by gel electrophoresis.

\section{ACKNOWLEDGMENTS}

This work was supported by the Finnish Cultural Foundation, Academy of Finland grant no. 202652 and Estonian Science Foundation grant no. 5939. We thank T. Turpen for TMV pBGC89 construct, L. Peil (University of Tartu) for help with materials, and S. Nõu for excellent plant care.

\section{LITERATURE CITED}

Ahola, T., and Kääriäinen, L. 1995. Reaction in alphavirus mRNA capping: Formation of a covalent complex of nonstructural protein nsP1 with 7-methyl-GMP. Proc. Natl. Acad. Sci. U.S.A. 92:507-511.

An, G. 1986. Development of plant promoter expression vectors and their use for analysis of differential activity of nopaline synthase promoter in transformed tobacco cells. Plant Physiol. 81:86-91.

Asurmendi, S., Berg, R. H., Koo, J. C., and Beachy, R. N. 2004. Coat protein regulates formation of replication complexes during Tobacco mosaic virus infection. Proc. Natl. Acad. Sci. U.S.A. 101:1415-1420.

Banerjee, N., Wang, J. Y., and Zaitlin, M. 1995. A single nucleotide change in the coat protein gene of Tobacco mosaic virus is involved in the induction of severe chlorosis. Virology 207:234-239.

Bao, Y., Carter, S. A., and Nelson, R. S. 1996. The 126- and 183-kilodalton proteins of Tobacco mosaic virus, and not their common nucleotide sequence, control mosaic symptom formation in tobacco. J. Virol. 70:6378-6383

Brigneti, G., Voinnet, O., Li, W.-X., Ji, L.-H., Ding, S.-W., and Baulcombe, D. 1998. Viral pathogenicity determinants are suppressors of transgene silencing in Nicotiana benthamiana. EMBO (Eur. Mol. Biol. Organ.) J. 17:6739-6746.

Chapman, E. J., Prokhnevsky, A. I., Gopinath, K., Dolja, V., and Carrington, J. 2004. Viral RNA silencing suppressors inhibit the microRNA pathway at an internal step. Genes Dev. 18:1179-1186.

Culver, J., Lehto, K., Close, S., Hilf, M., and Dawson, W. O. 1993. Genomic position affects the expression of Tobacco mosaic virus movement and coat protein genes. Proc. Natl. Acad. Sci. U.S.A. 90:2055-2059.

Dawson, W. O., Beck, D. L., Knorr, D. A., and Grantham, G. L. 1986. cDNA cloning of the complete genome of Tobacco mosaic virus and production of infectious transcripts. Proc. Natl. Acad. Sci. U.S.A. 83:18321836. 
Dawson, W. O., Bubrick, P., and Grantham, G. L. 1988. Modifications of the Tobacco mosaic virus protein gene affecting replication, movement and symptomatology. Phytopathology 78:783-789.

Ding, X. S., Liu, J., Cheng, N. H., Folimonov, A., Hou, Y. M., Bao, Y., Katagi, C., Carter, S. A., and Nelson, R. S. 2004. The Tobacco mosaic virus $126-\mathrm{kDa}$ protein associated with virus replication and movement suppresses RNA silencing. Mol. Plant-Microbe Interact. 17:583-592.

Dunoyer, P., Lecellier, C.-H., Parizotto, E. A. Himber, C., and Voinnet, O. 2004. Probing the microRNA and small interfering RNA pathways with virus-encoded suppressors of RNA silencing. Plant Cell 16:1235-1250.

Jockusck, H., Wiegand, C., Mersch, B., and Rajes, D. 2001. Mutants of Tobacco mosaic virus with temperature-sensitive coat protein induce heat shock response in tobacco leaves. Mol. Plant-Microbe Interact. 14:914-917.

Kawakami, S., Watanabe, Y., and Beachy, R. N. 2004. Tobacco mosaic virus infection spreads cell to cell as intact replication complexes. Proc. Natl. Acad. Sci. U.S.A. 101:6291-6296.

Kubota, K., Tsuda, S., Tamai, A., and Meshi, T. 2003. Tomato mosaic virus replication protein suppresses virus-targeted posttranscriptional gene silencing. J. Virol. 77:11016-11026.

Lecellier, C.-H., and Voinnet, O. 2004. RNA silencing: No mercy for viruses? Immun. Rev. 198:285-303.

Lehto, K., Tikkanen, M., Hiriart, J.-B., Paakkarinen, V., and Aro, E.-M. 2003. Depletion of the photosystem II core complex in mature tobacco leaves infected by the Flavum strain of Tobacco mosaic virus. Mol. Plant-Microbe Interact. 16:1135-1144.

Lindbeck, A. G. C., Lewandowski, D. J., Culver, J. N., Thomson, W. W., and Dawson, W. O. 1992. Mutant coat protein of Tobacco mosaic virus induces acute chlorosis in expanded and developing tobacco leaves. Mol. Plant-Microbe Interact. 5:235-241.

Mallory, A. C., Ely, L., Smith, T. H., Marethe, R., Anandalakshmi, R., Fagard, M., Vaucheret, H., Pruss, G., Bowman, L., and Vance, V. B. 2001. Hc-Pro suppression of transgene silencing eliminates the small RNAs but not transgene methylation or the mobile signal. Plant Cell 13:571-583.

Moore, C. J., Sutherland, P. W., Forster, R. L. S., Gardner, R. C., and
MacDiarmid, R. M. 2001. Dark green islands in plant virus infection are the result of posttranscriptional gene silencing. Mol. Plant-Microbe Interact. 14:939-946.

Rodman, M. K., Yadav, N. S., and Artus, N. N. 2002. Progression of geminivirus-induced transgene silencing is associated with transgene methylation. New Phytol. 155:461-468.

Sarmiento, C., Nigul, L., Kazantseva, J., Buschmann, M., and Truve, E. 2006. AtRLI2 is an endogenous suppressor of RNA silencing. Plant Mol. Biol. 61:153-163.

Shintaku, M. H., Carter, S. A., Bao, Y., and Nelson, R. S. 1996. Mapping nucleotides in the $126-\mathrm{kDa}$ protein gene that control the differential symptoms induced by two strains of Tobacco mosaic virus. Virology 221:218-225

Sijen, T., Wellink, J., Hiriart, J.-B., and van Kammen, A. 1996. RNA-mediated virus resistance: Role of repeated transgenes and delineation of targeted regions. Plant Cell 8:2277-2294.

Smith, H. A., Swaney, S. L., Parks, T. D., Wernsman, E. A., and Dougherty, W. G. 1994. Transgenic plant resistance mediated by untranslatable sense RNAs: Expression, regulation and fate of nonessential RNAs. Plant Cell 6:1441-1453.

Turpen, T. H., Turpen, A. M., Weinzettl, N., Kumagai, M. H., and Dawson, W. O. 1993. Transfection of whole plants from wounds inoculated with Agrobacterium tumefaciens containing cDNA of Tobacco mosaic virus. J. Virol. Methods 42:227-240.

Voinnet, O. 2005. Induction and suppression of RNA silencing: Insights from viral infections. Nat. Rev. Genet. 6:206-221.

Yelina, N. E., Savenkov, E. I., Solovyev, A. G., Morozov, S. Y., and Valkonen, J. P. T. 2002. Long distance movement, virulence, and RNA silencing suppression controlled by a single protein in hordei- and potyviruses: Complementary functions between virus families. J. Virol. 76:12981-12991.

Zvereva, S. D., Ivanov, P. A., Skulachev, M. V., Klyushin, A. G., Dorokhov, Y. L., and Atabekov, J. G. 2004. Evidence for contribution of an internal ribosome entry site to intercellular transport of a tobamovirus. J. Gen. Virol. 85:1739-1744. 